Michael G. Irwin MB ChB FRCA FHKAM, Robert C.H. Campbell MB ChB FRCA FHKAM,* Tsui Siu Lun MB BS FANZCA FHKAM, Joseph C.S. Yang MD FFARSCI FHKAM

\title{
Patient maintained alfentanil target- controlled infusion for analgesia during extracorporeal shock wave lithotripsy
}

All patients were ready for hospital discharge within one hour following treatment.

Purpose: The purpose of this study was to determine whether alfentanil given by a pharmacokinetic-based target controlled infusion (TCI) system under patient control is a suitable analgesic technique for extracorporeal shock wave lithotripsy (ESWL).

Methods: The design was an open, unblinded, noncompara. tive, prospective study. Forty outpatients undergoing ESWL were given patient maintained alfentanil TCI. Pain, nausea and sedation were assessed every 300 shocks. Vital signs were recorded every three minutes, pulse oximetry and electrocardiography being monitored continuously. Blood alfentanil concentration was measured for comparison with the predicted value.

Results: Alfentanil consumption (median $1.34 \mathrm{mg}$, range 0.8-3.6) and measured levels following treatment (median 60 $\mathrm{ng} \cdot \mathrm{ml}^{-1}$, range $\left.15.6-134.3\right)$ varied widely. The precision of the TCI system and the median prediction error (bias) were both $49 \%$. The median of pain scores recorded during treatment was 4 (range 0-8). The median respiration rate was 15 bpm (range 10-23), three patients required oxygen $\left(\mathrm{SaO}_{2}\right.$ $<92 \%$ ) Cardiovascular measurements were stable and there was no excessive sedation. The incidence of nausea was $15 \%$.

\section{Key words}

ANALGESIA: patient-controlled; target-controlled

infusion;

ANALGESICS: alfentanil;

SURGERY: urology; extracorporeal shock wave lithotripsy.

From the Department of Anaesthesiology, Queen Mary

Hospital and *Anaesthetic Unit, Prince Philip Dental Hospital, University of Hong Kong, Hong Kong.

Address correspondence to: Dr. Michael G. Irwin,

Department of Anaesthesiology, University of Hong Kong, Room 415, K Block, Queen Mary Hospital, Pokfulam Road, Hong Kong.

Accepted for publication 13th May, 1996.
Conclusions: Patient maintained alfentanil TCI provides good analgesia for ESWL in the majority of patients with little sedation. Respiratory depression is uncommon but supplementary oxygen should be given prophylactically. There is considerable interindividual variation in demand for alfentanil indicating the usefulness of the patient control method. The TCI system underestimated alfentanil blood concentrations but this did not affect its clinical usefulness.

Objectif: Déterminer l'alfentanil en perfusion autocontrôlée à modelage pharmacocinétique assistée par ordinateur (PAO) constitue une technique analgésique appropriée à la lithotripsie extracorporelle par ondes de choc (LEOC).

Méthodes: Étude ouverte, non comparative et prospective. Quarante patients ambulatoires programmés pour une lithotripsie extracorporelle par onde de choc ont obtenu une PAO chargée à l'alfentanil. La douleur, la nausée et la sédation ont été évaluées après chaque série de 300 chocs. Les signes vitaux ont été enregistrés à toutes les trois minutes pendant que l'oxymétrie de pouls et l'électrocardiographie étaient monitorées en continu. Les concentrations sanguines d'alfentanil étaient déterminées pour fin de comparaison avec les valeurs prédites.

Résultats: La consommation d'alfentanil (médiane 1,34 mg. écart $0,8-3,6)$ et les niveaux mesurés après le traitement (médiane $60 \mathrm{ng} \cdot \mathrm{ml}^{-1}$, écart 15,6-134,3) variaient considérablement. La précision du système de PAO et celle de l'erreur médiane (biais) étaient toutes deux à 49\%. La médiane du score de douleur enregistré pendant le traitement était de 4 (écart 0-8). La fréquence respiratoire médiane était de $15 \mathrm{rpm}$ (écart 10-23). Trois patient ont eu besoin d'oxygène $\left(\mathrm{SaO}_{2}<92 \%\right)$. Les paramètres cardiovasculaires étaient stables et la sédation n'était pas exagérée. L'incidence de la nausée était de $15 \%$. Tous les patients ont obtenu leur congé une heure après le traitement.

Conclusion: La perfusion de d'alfentanil maintenue par PAO 
procure une bonne analgésie pour la lithotripsie par ondes de choc. La dépression respiratoire est rare mais un supplément prophylactique d'oxygène devrait être administré. La demande individuelle d'alfentanil varie beaucoup entre les sujets, ce qui démontre l'intérêt de la méthode autocontrôlée. Le système de PAO sous-estime les concentrations sanguines d'alfentanil mais ceci n'affecte pas ses bénéfices en clinique.

Extracorporeal shock wave lithotripsy (ESWL) was first introduced for the treatment of urinary tract stones in Germany in $1980 .^{\prime}$ Subsequent development and refinement of the technique has led to its world-wide acceptance as an effective non-invasive therapy virtually superseding open surgery. The latest generation lithotripters offer immersion-free treatment and produce a shock wave that enters the body over a much larger skin surface area. This produces better distribution of energy and usually obviates the need for general or epidural anaesthesia. However, the procedure is still painful and most patients tolerate it much better with the administration of intravenous opioid analgesics and sometimes anxiolytics. An audit of ESWL treatment in our hospital showed that $62.8 \%$ of patients required iv meperidine $(40.7 \%)$ or diazepam $(5.5 \%)$ or both $(16.6 \%)$ in order to tolerate it, $^{2}$ and similar drug regimens have been recommended by other workers. ${ }^{3}$ Pain intensity is greatest during shock wave impact and there is generally no need for powerful analgesia after treatment. Use of these drugs involves interrupting treatment, to titrate the required dose, and their relatively long duration of action can lead to delayed recovery and discharge. There is also considerable interindividual variation in analgesic requirements. ${ }^{3,4}$

Patient-controlled analgesia (PCA) is a potentially attractive technique despite limited experience with it in this setting. Alfentanil, a potent synthetic opioid, has a low tissue solubility which ensures a rapid onset and short latency to peak effect..$^{5}$ This, together with its relatively short duration of action, has made it a popular drug for the management of shock wave related pain. ${ }^{6-9}$ Various modes of administration have been tried including physician titrated infusion, 7,8 and PCA bolus dosing. ${ }^{9}$ We have evaluated a new technique of pharmacokinetic-based infusion of alfentanil where the target plasma concentration of the drug is maintained by patient demand.

\section{Methods}

The study was approved by the University of Hong Kong Ethics Committee and all patients gave written informed consent. We evaluated 40 unpremedicated ASA physical status I and II patients undergoing elec- tive ESWL for upper urinary tract calculi on a Dornier MFL 5000 lithotripter. Exclusion criteria included age $<18 \mathrm{yr}$, history of drug or alcohol abuse, or an allergic reaction to opioid drugs. Eighteen patients had been treated before with ESWL and had required iv meperidine for analgesia while the other 22 patients had no previous experience of ESWL.

After routine preoperative evaluation, the patients were positioned on the lithotripsy table and baseline measurements of blood pressure, heart rate, oxygen saturation $\left(\mathrm{SaO}_{2}\right)$ and respiratory rate (RR) were obtained using a Dinamap non-invasive automatic blood pressure cuff, an electrocardiogram, a pulse oximeter (Nellcor), and a pneumatic respiration sensor (Graesby), respectively. A $20 \mathrm{G}$ iv cannula was inserted and connected to an infusion of saline $0.9 \%$. Patient-controlled analgesia was provided using a target-controlled infusion (TCI) of alfentanil (IVC 9000, Anaesthesia Technology, Wetherby, England) through a one-way valve system connected to the patient end of the iv infusion. The TCI system consists of an Ohmeda 9000 infusion pump with a modified backbar containing computer hardware which is programmed with pooled pharmacokinetic data for a patient population. ${ }^{10,11}$ When the system is switched on it prompts the operator to enter the proposed patient's age, weight and sex and the blood concentration of alfentanil one wishes to achieve in that patient. Using a three-compartment pharmacokinetic model, it will then calculate the bolus dose of alfentanil required to achieve that target concentration and the infusion rate required to maintain it. With this system, when pain relief is required, the target concentration of alfentanil can be increased by the patient pushing twice within one second on a demand button. The resultant increase in the alfentanil infusion rate will increase the predicted plasma concentration by $5 \mathrm{ng} \cdot \mathrm{ml}^{-1}$. There is a lockout interval of two minutes. If analgesia is not demanded within $15 \mathrm{~min}$ the target concentration is reduced by $5 \mathrm{ng} \cdot \mathrm{ml}^{-1}$. If, subsequently, the button is not pushed, the $5 \mathrm{ng} \cdot \mathrm{ml}^{-1}$ decline will continue every 15 min until the baseline value of $15 \mathrm{ng} \cdot \mathrm{ml}^{-1}$ is reached.The initial target concentration was set at 30 $\mathrm{ng} \cdot \mathrm{ml}^{-1}$ as this has been proposed by other workers to be around the minimum effective analgesic concentration for alfentanil. ${ }^{12,13}$ The patients were then given control of the handset, having been instructed earlier in its use.

After stone localisation and imaging, ESWL treatment was commenced. Shock wave generator voltage was started at $14 \mathrm{kV}$ and rapidly increased in $2 \mathrm{kV}$ increments to a maximum of $24 \mathrm{kV}$. The number of shock wave discharges and the generator voltages used were recorded and a shock wave energy index (SEI) was 
calculated (generator voltage squared multiplied by the number of shock waves). ${ }^{9}$ This index was determined as an approximation of the total quantity of applied shock wave energy. The duration of treatment and percentage stone fragmentation were also noted.

The patients were continuously observed by one of the investigators (MI or RC). Blood pressure, heart and respiratory rates were recorded every three minutes. The ECG and $\mathrm{SaO}_{2}$ were monitored continuously and any patient whose oxygen saturation decreased below $92 \%$ was given supplementary oxygen at $2 \mathrm{~L} \cdot \mathrm{min}^{-1}$ via nasal cannulae. Pain, sedation and emesis were evaluated after each 300 shocks during treatment. Pain was assessed by the patient and recorded using an 11 point (0-10) numerical rating score (NRS).$^{14}$ Sedation was assessed by the observer and scored as follows: $4=$ restless/ anxious, 3 = awake/calm, 2 = drowsy, 1 = asleep but easily roused, $0=$ asleep but difficult to rouse. Emesis was assessed by the patient and scored as: 2 = vomiting, $1=$ nauseous, $0=$ none.

The predicted plasma alfentanil concentration was also recorded every 300 shocks and a venous blood sample was taken from the contralateral arm at the end of treatment, before stopping the TCI. These samples were centrifuged and the plasma stored at $-20^{\circ} \mathrm{C}$ for later batch analysis by High Performance Liquid Chromatography based on the method described by Kumar and colleagues. ${ }^{15}$

Median pain and sedation scores were calculated for each patient following treatment and the occurrence of emesis or other side-effects noted. Patient satisfaction was assessed by open ended non structured verbal questions with the answers recorded in writing. Those who had had previous ESWL were asked to compare it with the previously used analgesic method. Patients were discharged if they were able to walk unaided, were free of pain and nausea and had normal vital signs between 45 and $60 \mathrm{~min}$ following the end of treatment.

The accuracy of the TCI was calculated by comparing measured blood concentrations of alfentanil ( $\mathrm{Cam}$ ) with the corresponding TCI system predicted value (Cap). The performance error was calculated for each data point as follows :

Performance error $=\frac{C a m-C a p}{C a p} \times 100^{16.17}$

Bias is defined as the median performance error for all blood samples: A positive bias indicates the system has a tendency to overestimate the measured concentration of serum alfentanil and vice versa. Inaccuracy is defined as the median of the absolute values of the individual performance errors and is a measure of the degree of scatter of the data about a line of perfect pre-
TABLE I Patient details. Age - mean (range); weight - mean (SD); others - median (range)

\begin{tabular}{lc}
\hline Age $(\mathrm{yr})$ & $51.03(28-77)$ \\
Sex $(\mathrm{M}: \mathrm{F})$ & $26: 14$ \\
Weight $(\mathrm{kg})$ & $61.03(9.62)$ \\
Duration of treatment & $60.5(30-86)$ \\
Number of shock waves & $3000(1522-3200)$ \\
Stone fragmentation (\%) & $80(50-100)$ \\
Average generator voltage setting $(\mathrm{kV})$ & $22(18.8-24.2)$ \\
Shock wave energy index* & $13.7(5.6-16.3)$ \\
\hline
\end{tabular}

*SEI calculated by the following formula:

$\frac{\left(n_{1} \times U_{1}\right)+\left(n_{2} \times U_{2}\right)+\left(n_{y} \times U_{y}\right)}{10^{5} k V^{2}}$

where $n_{n}=$ number of shock waves; $U_{n}=$ corresponding generator voltage setting.

TABLE II Respiratory, pain and sedation data during treatment. Median (range)

\begin{tabular}{lc}
\hline Respiratory rate $\left(\right.$ breaths $\cdot$ min $\left.^{-1}\right)$ & $15(10-23)$ \\
Numerical pain rating score & $4(0-8)$ \\
Sedation score & $3(2-4)$ \\
\hline
\end{tabular}

diction. ${ }^{18}$ Statistical analyses were performed using the software programme Statistica release 4.5 (StatSoft $^{\mathrm{TM}}$, Tulsa $^{\mathrm{TM}}$, Oklahoma, USA).

\section{Results}

Patient demographic and shock wave lithotripsy data are shown in Table I. The proposed treatment could be completed in all patients with no patient intolerance. Six patients $(15 \%)$ experienced some nausea during treatment or shortly afterwards, however this was shortlived, did not interrupt treatment, required no pharmacotherapy and no vomiting occurred.

Median pain and sedation scores and respiration rate during the lithotripsy procedure were first calculated for each individual patient. These data were then grouped and the median and range of the group data is displayed in Table II. The lowest recorded respiratory rate was nine bpm and airway obstruction did not occur. However, three patients $(7.5 \%)$ had a decrease in $\mathrm{SaO}_{2}$ to $<92 \%$ which was easily and rapidly corrected by the administration of supplementary oxygen.

Haemodynamic changes were assessed by calculating the average mean blood pressure and heart rate for all patients at baseline (before ESWL or alfentanil were commenced) and at increments of 300 shock waves. There was little variability from baseline measurements and no incidence of hypertension, hypotension or arrhythmia.

All patients expressed high satisfaction with the technique. Of the 18 who had previous experience of ESWL 
TABLE III Alfentanil data. Median (range)

Alfentanil consumption (mg)

$1.49(0.8-3.6)$

Alfentanil consumption $\left(\mu \mathrm{g} \cdot \mathrm{kg}^{-1} \cdot \mathrm{min}^{-1}\right)$

Max. predicted alfentanil level $\left(\mathrm{ng} \cdot \mathrm{ml}^{-1}\right)$

$0.41(0.18-0.81)$

$45(30-110)$

Actual measured alfentanil level at end $\left(\mathrm{ng} \cdot \mathrm{ml}^{-1}\right) \quad 60(15.6-134.3)$

with meperidine analgesia, 17 strongly preferred the technique under investigation. Reasons cited were superior analgesia, self-titration, and being less "sleepy" afterwards. One patient preferred meperidine because he felt the analgesia was comparable to alfentanil but meperidine made him feel more sedated.

All patients fulfilled our standard discharge criteria and were allowed to leave the unit within one hour following the end of treatment. No further analgesia was required during the recovery period.

Data concerning alfentanil consumption, measured and predicted concentrations are displayed in Table III. There was considerable interindividual variability in alfentanil consumption and measured concentrations at the end of treatment. Each measured blood concentration of alfentanil was compared with its corresponding delivery system prediction (Figure 1 ) and the correlation coefficient calculated to be 0.703 ( $n=40, P<0.001)$. The percentage performance error was also calculated for each measured concentration and plotted against the predicted alfentanil concentration (Figure 2), showing the majority of the data points lie above the line of perfect prediction. The population median performance error (bias) and inaccuracy were both $49 \%$ revealing the tendency of the TCI system to underpredict the actual measured values of blood alfentanil.

\section{Discussion}

The Dornier MFL 5000 machine used in our institution is a second-generation lithotripter that utilises an enlarged ellipsoid to distribute the shock waves on a greater surface area of skin while still converging on the target. Shock wave coupling is achieved with an in-built water filled cushion and is thus bath-free.

The pain of lithotripsy is experienced where energy is transferred at each tissue interface and occurs not only at the water-skin interface, but also at tissues near the target area of the device, leading to visceral and organ pain in addition. This explains why skin surface local anaesthetic techniques have not been very successful in reducing discomfort. ${ }^{19,20}$ Pain is proportional to the amount of energy contained in each shock wave and can be reduced by decreasing the voltage used for shock wave generation. However, although this increases patient tolerance, it also reduces the success rate of each session. ${ }^{21}$

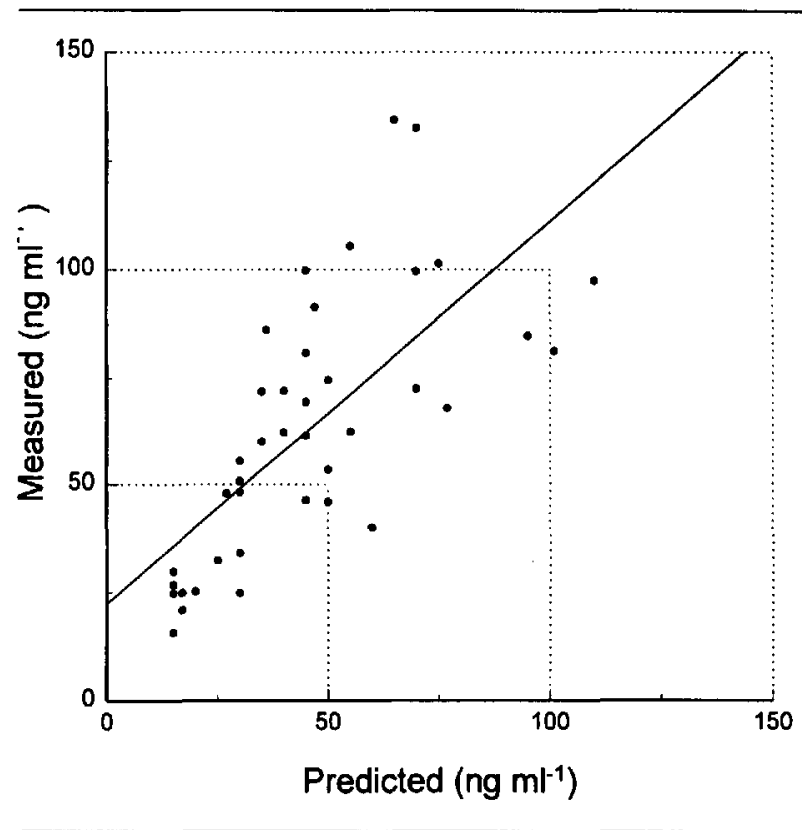

FIGURE 1 Correlation between predicted and measured plasma concentrations of alfentanil. $n=40, y=22.36+0.887 x(r=0.703)$

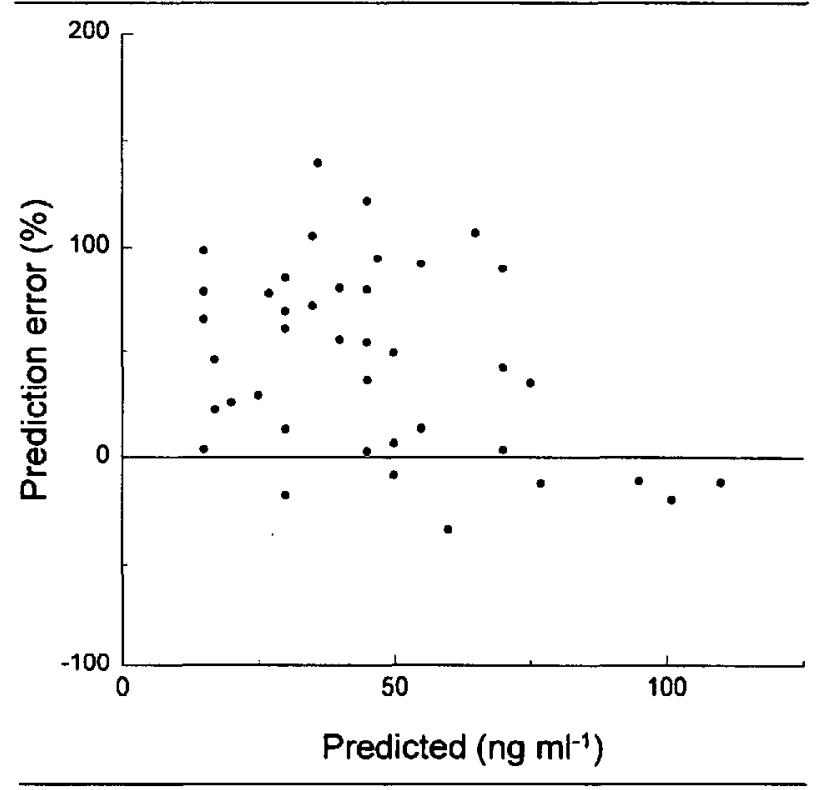

FIGURE 2 Comparison between prediction error (\%) and predicted values of plasma concentrations of alfentanil. Bias and precision $49 \%$.

Effective analgesia simplifies stone imaging and targeting by reducing patient movement during shock wave impact and allows the use of high acoustic energies which increase fragmentation efficiency. We were able to deliver high shock wave energy levels without interruption to all our patients thereby producing a high percentage stone fragmentation. Although the treatment 
still involved some degree of pain, it was easily tolerated with minimal change in cardiovascular variables from baseline measurements.

In common with all opioid agonist drugs, alfentanil causes a dose-related depression of respiration and $7.5 \%$ of our patients had a decrease in oxygen saturation to around $90 \%$ during treatment. There was no airway obstruction and desaturation was rapidly corrected by simple oxygen therapy. This is most likely to be a result of hypoventilation and, since it did not occur with bradypnoea, is probably related to a reduction in the depth of respiration. We recommend the concurrent prophylactic administration of oxygen $2 \mathrm{~L} \cdot \mathrm{min}^{-1}$ by nasal cannulae in all patients using this analgesic technique as it is effective, inexpensive and of minimal discomfort.

Another troublesome opioid side-effect is emesis and $15 \%$ of patients experienced nausea although there was no vomiting. The nausea occurred at the end of treatment, following transfer to the recovery room and may have been compounded by patient movement. We have found it useful to encourage patients to lie still with no oral fluid intake for about $15 \mathrm{~min}$ after ESWL since this was the time that dizziness and nausea were most likely.

In order to improve patient co-operation during ESWL, analgesic induced sedation should be mild. There is also an association between deep sedation and adverse outcome with the use of sedo/analgesic techniques during various interventional procedures. ${ }^{22}$ Other workers have suggested that, at equianalgesic plasma concentrations, alfentanil may produce unwanted effects of less intensity compared with morphine and other mureceptor agonists, ${ }^{23-25}$ and that there is little sedation associated with postoperative alfentanil analgesia. ${ }^{26-28}$ There was no excessive sedation or disorientation during or after treatment in any of our patients and full cooperation was maintained at all times.

Analgesic requirements during ESWL are difficult to predict, ${ }^{4}$ and we have shown a wide range in both total dose delivered and plasma alfentanil drug concentrations. Our population was slightly biased, in that we selected 18 patients with a previous painful ESWL experience which they had difficulty tolerating, but this was useful in providing a crossover comparison with the traditional analgesic technique. Patient-controlled administration of analgesic drugs is an effective and well established technique for the management of acute pain and the pharmacological and psychological advantages have been extensively investigated and reviewed. ${ }^{29,30}$ It has also been shown to be an effective analgesic technique for shock wave treatment. ${ }^{31}$ Alfentanil, because of its rapid distribution and elimination, is ideally administered to spontaneously breathing patients by titrated infusion rather than intermittent bolus injec-tions. ${ }^{28}$ This is in order to maintain a more stable plasma alfentanil concentration above the MEAC and avoid large fluctuations in concentration. Previously, this was performed by the attending physician as patient control was only possible with bolus drug administration. However, using this TCI system, patients were able to achieve rapidly and then maintain an effective analgesic concentration by self-titration and without interrupting treatment, thus combining the benefits of continuous infusion with patient control.

Analysis of plasma alfentanil concentrations indicates that the TCI system had a tendency to underestimate actual drug concentration particularly at lower concentrations. This was not a problem in the clinical use of the device as the patient-controlled delivery technique allowed each patient to titrate the systemic concentration of alfentanil to a value appropriate for overall comfort. Although this value may not have been predicted accurately, the system was able to make proportional changes in the concentrations, allowing rapid titration of drug concentration to effect. This provided good quality analgesia with alfentanil in patients with a wide range of ages and produced high patient satisfaction and no delay in discharge.

We used the population alfentanil pharmacokinetic data of Maitre et al. ${ }^{10}$ and an evaluation of these by Raemer $e t$ al. also found a relatively large bias and inaccuracy (both $+53 \%$ ) in their patients, ${ }^{17}$ although the performance was more satisfactory when employed recently in another study. ${ }^{32}$ Raemer et al. produced much more reliable and accurate target blood concentrations using the pharmacokinetic variables of Scott $e t a l . .^{33}$ and perhaps these would also have been better for our patients. More extensive testing of these pharmacokinetic models in Oriental patients is required with a view to adjusting the algorithm to improve its accuracy in this population.

It is concluded that this is an effective administration system for alfentanil. It helps patients to tolerate ESWL by allowing them to rapidly self-titrate the drug infusion to their MEAC producing good analgesia and minimising side-effects. It produces little sedation and has proven to be a suitable technique for outpatients.

\section{References}

1 Chaussy $C H$, Brendel W, Schmiedt E. Extracorporeally induced destruction of kidney stones by shock waves. Lancet 1980; ii: 1265-8.

2 Chui $A K K$, Tse $H W$, Tam PC. Extracorporeal shock wave lithotripsy. Journal of the Hong Kong Medical Association 1993; 45: 215-7.

3 Allman DB, Richlin DM, Ruttenberg $M$, Sotolongo JR Jr. Analgesia in anesthesia-free extracorporeal shock wave 
lithotripsy: a standardized protocol. J Urol 1991; 146: 718-20.

4 Dawson C, Vale JA, Corry DA, et al. Choosing the correct pain relief for extracorporeal lithotripsy. Br J Urol 1994; 74: 302-7.

5 Hug CC Jr, Chaffman M, Camu F, Spierdijk J. Pharmacokinetic properties of alfentanil. In: Alfentanil: Pharmacology and Uses in Anaesthesia. New Zealand: Adis Press, 1984: 2-21.

6 Freilich JD, Brull SJ, Schiff S, Silverman DG, Houde C, Schrier RI. Anesthesia for lithotripsy: efficacy of monitored anesthesia care with alfentanil. Anesth Analg 1990; 70: S115.

7 Connelly NR, Weinstock $A D$. Continuous alfentanil infusion for extracorporeal shock wave lithotripsy of gallbadder stones. Anesth Analg 1990; 70: 299-302.

8 Schelling $G$, Weber W, Sackmann M, Peter K. Pain control during extracorporeal shock wave lithotripsy of gallstones by titrated alfentanil infusion (Letter). Anesthesiology 1989; 70: 1022-3.

9 Schelling $G$, Mendl $G$, Weber $W$, et al. Patient controlled analgesia for extracorporeal shock wave lithotripsy of gallstones. Pain 1992; 48: 355-9.

10 Maitre PO, Vozeh S, Heykants J, Thomson DA, Stanski $D R$. Population pharmacokinetics of alfentanil: the average dose-plasma concentration relationship and interindividual variability in patients. Anesthesiology 1987; 66: 3-12.

11 Davies FW, White $M$, Kenny GNC. Postoperative analgesia using a computerised infusion of alfentanil following aortic bifurcation graft surgery. Int J Clin Monit Comput 1992; $9: 207-12$.

12 Lehmann KA, Ribbert N, Horrichs-Haermeyer G. Postoperative patient-controlled analgesia with alfentanil: analgesic efficacy and minimum effective concentrations. J Pain Symptom Manage 1990; 5: 249-58.

13 Owen $H$, Currie JC, Plummer JL. Variation in the blood concentration/analgesic response relationship during patient-controlled analgesia with alfentanil. Anaesth Intensive Care 1991; 19: 555-60.

$14 \mathrm{Katz}$, Melzack R. Measurement of pain. Anesthesiology Clinics of North America. 1992; 10: 229-45.

15 Kumar K, Morgan DJ, Crankshaw DP. Determination of fentanyl and alfentanil in plasma by high-performance liq uid chromatography with ultraviolet detection. J Chromatogr B Biomed Appl 1987; 419: 464-8.

16 Glass PS, Goodman DK, Ginsberg B, Reves JG, Jacobs $J R$. Accuracy of pharmacokinetic model-driven infusion of propofol. Anesthesiology 1989; 71:A277.

17 Raemer DB, Buschman A, Varvel JR, et al. The prospective use of population pharmacokinetics in a computer-driven infusion system for alfentanil. Anesthesiology 1990; 73: $66-72$.
18 Varvel JR, Donoho DL, Shafer $S L$. Measuring the predictive performance of computer-controlled infusion pumps. J Pharmacokinet Biopharm 1992; 20: 63-94.

19 Monk TG, Ding Y, White PF, Albala DM, Clayman RV. Effect of topical eutectic mixture of local anesthetics on pain response and analgesic requirement during lithotripsy procedures. Anesth Analg 1994; 79: 506-11.

20 Bierkens AF, Maes RM, Hendrikx AJM, Erdos AF, de Vries JDM, Debruyne FMJ. The use of local anesthesia in second generation extracorporeal shock wave lithotripsy: eutectic mixture of local anesthetics. J Urol 1991; 146: 287-9.

21 Pettersson B, Tiselius $H-G$, Andersson A, Eriksson I. Evaluation of extracorporeal shock wave lithotripsy without anesthesia using a Domier HM3 lithotriptor without technical modifications. J Urol 1989; 142: 1189-92.

22 Daneshmend TK, Bell GD, Logan RFA. Sedation for upper gastrointestinal endoscopy: results of a nationwide survey. Gut 1991; 32: 12-5.

23 Andrews CJH, Sinclair M, Prys-Roberts C, Dye A. Ventilatory effects during and after continuous infusion of fentanyl or alfentanil. Br J Anaesth 1983; 55: 211S-6.

24 Scamman FL, Ghoneim MM, Korttila K. Ventilatory and mental effects of alfentanil and fentanyl. Acta Anesthesiol Scand 1984; 28: 63-7.

25 White PF, Coe V, Shafer A, Sung M-L. Comparison of alfentanil with fentanyl for outpatient anesthesia. Anesthesiology 1986; 64: 99-106.

26 Owen H, Brose WG, Plummer JL, Mather LE. Variables of patient-controlled analgesia. 3: test of an infusiondemand system using alfentanil. Anaesthesia 1990, 45: 452-5.

27 Welchew EA, Hosking J. Patient-controlled postoperative analgesia with alfentanil. Anaesthesia 1985; 40: 1172-7.

28 Hill HF, Coda BA, Mackie AM, Iverson $K$. Patient-controlled analgesic infusions: alfentanil versus morphine. Pain 1992; 49: 301-10.

29 Ferrante FM. Patient-controlled analgesia. Anesthesiology Clinics of North America 1992; 10: 287-98.

30 Mather $L E$, Owen $H$. The scientific basis of patient-controlled analgesia. Anaesth Intensive Care 1988; 16: 427-36.

31 Schelling $G$, Weber W, Mendl G,Braun H, Cullman $H$. Patient controlled analgesia for shock wave lithotripsy: the effect of self-administered alfentanil on pain intensity and drug requirement. J Urol 1996; 155: 43-7.

32 van den Nieuwenhuyzen MCO, Engbers FHM, Burm AGL, Vletter AA, van Kleef JW, Bovill JG. Computer-controlled infusion of alfentanil versus patient-controlled administration of morphine for postoperative analgesia: a doubleblind randomized trial. Anaesth Analg 1995; 81: 671-9.

33 Scott JC, Ponganis KV, Stanski DR. EEG quantitation of narcotic effect: the comparative pharmacodynamics of fentanyl and alfentanil. Anesthesiology 1985; 62: 234-41. 